\title{
ORIGINAL
}

\section{Management of arterial partial pressure of carbon dioxide in the first week after traumatic brain injury: results from the CENTER-TBI study}

\author{
Giuseppe Citerio ${ }^{1,2^{*}} \mathbb{D}$, Chiara Robba ${ }^{3,4}$, Paola Rebora ${ }^{1,5}$, Matteo Petrosino ${ }^{5}$, Eleonora Rossi ${ }^{6}$, Letterio Malgeri ${ }^{7}$, \\ Nino Stocchetti ${ }^{8,9}$, Stefania Galimberti ${ }^{1,5}$, and David K. Menon ${ }^{10}$ on behalf of the Center-TBI participants and \\ investigators
}

(c) 2021 The Author(s)

\begin{abstract}
Purpose: To describe the management of arterial partial pressure of carbon dioxide $\left(\mathrm{PaCO}_{2}\right)$ in severe traumatic brain-injured (TBI) patients, and the optimal target of $\mathrm{PaCO}_{2}$ in patients with high intracranial pressure (ICP).

Methods: Secondary analysis of CENTER-TBI, a multicentre, prospective, observational, cohort study. The primary aim was to describe current practice in $\mathrm{PaCO}_{2}$ management during the first week of intensive care unit (ICU) after TBI, focusing on the lowest $\mathrm{PaCO}_{2}$ values. We also assessed $\mathrm{PaCO}_{2}$ management in patients with and without ICP monitoring $\left(\mathrm{ICP}_{\mathrm{m}}\right)$, and with and without intracranial hypertension. We evaluated the effect of profound hyperventilation (defined as $\mathrm{PaCO}_{2}<30 \mathrm{mmHg}$ ) on long-term outcome.

Results: We included 1100 patients, with a total of 11,791 measurements of $\mathrm{PaCO}_{2}(5931$ lowest and 5860 highest daily values). The mean ( \pm SD) $\mathrm{PaCO}_{2}$ was $38.9( \pm 5.2) \mathrm{mmHg}$, and the mean minimum $\mathrm{PaCO}_{2}$ was $35.2( \pm 5.3)$ $\mathrm{mmHg}$. Mean daily minimum $\mathrm{PaCO}_{2}$ values were significantly lower in the ICP $\mathrm{m}$ group (34.5 vs $36.7 \mathrm{mmHg}, p<0.001$ ). Daily $\mathrm{PaCO}_{2}$ nadir was lower in patients with intracranial hypertension ( $33.8 \mathrm{vs} 35.7 \mathrm{mmHg}, p<0.001$ ). Considerable heterogeneity was observed between centers. Management in a centre using profound hyperventilation (HV) more frequently was not associated with increased 6 months mortality $(\mathrm{OR}=1.06,95 \% \mathrm{Cl}=0.77-1.45, p$ value $=0.7166)$, or unfavourable neurological outcome (OR $1.12,95 \% \mathrm{Cl}=0.90-1.38, p$ value $=0.3138)$.
\end{abstract}

Conclusions: Ventilation is manipulated differently among centers and in response to intracranial dynamics. $\mathrm{PaCO}_{2}$ tends to be lower in patients with ICP monitoring, especially if ICP is increased. Being in a centre which more frequently uses profound hyperventilation does not affect patient outcomes.

Keywords: Carbon dioxide, Hyperventilation, Traumatic brain injury, Intracranial pressure, Outcome

\footnotetext{
*Correspondence: giuseppe.citerio@unimib.it

${ }^{1}$ School of Medicine and Surgery, University of Milano - Bicocca, Monza, Italy

Full author information is available at the end of the article
}

Giuseppe Citerio and Chiara Robba equally contributed as first authors to this work. Stefania Galimberti and David K. Menon equally contributed as last authors to this work.

CENTER-TBI ICU participants and investigators are listed as non-author contributors in the Acknowledgement section.

\section{记) Springer}

\section{Introduction}

Changes in the arterial partial pressure of carbon dioxide $\left(\mathrm{PaCO}_{2}\right)$, by modifying the extravascular $\mathrm{pH}$, modulate cerebrovascular tone, and hence cerebral blood flow (CBF) and cerebral blood volume (CBV) [1, 2]. Hypercapnia results in perivascular acidosis, which causes cerebral vasodilation, and consequently, an increase in intracranial volume. In patients with poor intracranial compliance, this could raise intracranial pressure (ICP). On the other 
hand, hyperventilation (HV) induced alkalosis reduces vascular calibre, and hence $\mathrm{CBV}$, and can represent an effective measure to control intracranial hypertension, when ICP remains elevated despite first-line therapies [3-6]. However, hypocapnic cerebral vasoconstriction can also reduce $\mathrm{CBF}$ [7], thus posing the risk of secondary ischaemic insults [8]. In a survey across European trauma centers, the most frequently reported $\mathrm{PaCO}_{2}$ target was $36-40 \mathrm{mmHg}$ in the absence of intracranial hypertension, which was reduced to $30-35 \mathrm{mmHg}$ when ICP was $>20 \mathrm{mmHg}$ [9]. The most recent evidence-based guidelines on TBI management provide no definitive recommendations regarding target $\mathrm{PaCO}_{2}$ levels due to the low quality of evidence available on this issue $[10,11]$.

Consequently, although many patients with severe TBI undergo several days of mechanical ventilation, there is little evidence-based guidance on $\mathrm{PaCO}_{2}$ targets, and clinical practice remains highly variable. A recent consensus on mechanical ventilation in patients with acute brain injury suggested aiming for a physiologic range of $\mathrm{PaCO}_{2}$ between 35 and $45 \mathrm{mmHg}$ [12], and to only use hyperventilation (with an undefined $\mathrm{PaCO}_{2}$ target) as a short-term therapeutic option in patients with evidence of brain herniation. However, the document was unable to provide a recommendation on the use of hyperventilation in patients who showed significant ICP elevation, but no evidence of herniation. A management algorithm for patients with intracranial hypertension, based on expert consensus, suggested the use of $\mathrm{HV}\left(\mathrm{PaCO}_{2} 32-35 \mathrm{mmHg}\right)$ for controlling ICP only as a second-tier treatment, did not support lower $\mathrm{PaCO}_{2}$ levels and recommended against routine hyperventilation to $\mathrm{PaCO}_{2}$ below $30 \mathrm{mmHg}$ [13].

The objectives of this study were to assess, in a realworld context, $\mathrm{PaCO}_{2}$ management and the lowest target of $\mathrm{PaCO}_{2}$ in a large cohort of mechanically ventilated TBI patients and practice variability between centres to evaluate the association between the use of profound HV and 6-month clinical outcomes.

\section{Methods}

\section{Study design and patients}

The Collaborative European NeuroTrauma Effectiveness in Research in Traumatic Brain Injury (CENTERTBI study, registered at clinicaltrials.gov NCT02210221) is a longitudinal, prospective collection of data from TBI patients across 65 centers in Europe. The study was conducted between December 19th, 2014, and December 17th, 2017 and details regarding the design and the results of the screening and enrolment process have been previously described [14-16].

The CENTER-TBI study was approved by the Medical Ethics Committees in all participating centers, and

\section{Take-home message}

The manipulation of arterial carbon dioxide levels $\left(\mathrm{PaCO}_{2}\right)$ is easy, and hyperventilation (HV) has been a common ICP-lowering strategy for over half a century. However, hyperventilation-induced vasoconstriction is a double-edged sword. It reduces cerebral blood volume and intracranial volume, and therefore, lowers ICP

We observed huge variability among centers in $\mathrm{PaCO}_{2}$ values and use of HV. Although causal inferences cannot be drawn from these observational data, our results suggest that, in patients with severe intracranial hypertension, $\mathrm{HV}$ is not associated with worse long-term clinical outcome

informed consent was obtained according to local regulations (https://www.center-tbi.eu/project/ethic al-approval). This project on $\mathrm{PaCO}_{2}$ management was preregistered on the CENTER-TBI proposal platform and approved by the CENTER-TBI proposal review committee before starting the analysis (ESM Document 1 ). This report complies with the Strengthening the Reporting of Observational Studies in Epidemiology (STROBE) reporting guidelines (ESM Table S1).

We included all patients in the CENTER-TBI Core study who had a TBI necessitating ICU admission, required tracheal intubation and mechanical ventilation, had at least two $\mathrm{PaCO}_{2}$ measurements in the first 7 days and had been admitted to a study centre that enrolled at least ten patients.

\section{Data collection and definitions}

Detailed information on data collection is available on the study website (https://www.center-tbi.eu/data/dicti onary). For the first week in ICU, the daily lowest and highest $\mathrm{PaCO}_{2}$ values from arterial blood gases and, if an ICP device was inserted, the hourly ICP measures were used for analysis.

$\mathrm{HV}$ was defined as moderate for $\mathrm{PaCO}_{2}$ ranging between 30 and $35 \mathrm{mmHg}$ and profound for $\mathrm{PaCO}_{2}<30 \mathrm{mmHg}[10,13]$. Therapy intensity level (TIL) was calculated according to the most recent TIL scale [17]. Patients with invasive ICP monitoring during the first week of ICU stay were classified as $\mathrm{ICP}_{\mathrm{m}}$, while those who did not receive ICP monitoring during ICU stay as no- $\mathrm{ICP}_{\mathrm{m}}$. Intracranial hypertension was defined as $\mathrm{ICP}>20 \mathrm{mmHg}$.

\section{Objectives}

The aims of this study are:

1. to describe the $\mathrm{PaCO}_{2}$ values in the first week from ICU admission in mechanically ventilated TBI patients, and to evaluate practice variability across centers, particularly focusing on the lowest targets of $\mathrm{PaCO}_{2}$; 
2. to assess at a center level the $\mathrm{PaCO}_{2}$ management in patients with/without ICP monitoring and with/ without intracranial hypertension;

3. to evaluate the association between patient outcomes and center propensity to use profound HV.

\section{Outcomes}

Mortality and functional outcome (measured as the Extended Glasgow Outcome Score, GOSE) were assessed at 6 months. All responses were obtained by study personnel from patients or from a proxy (where impaired cognitive capacity prevented patient interview), during a face-to-face visit, by telephone interview, or by postal questionnaire around 6 months after injury [18]. All evaluators had received training in the use of the GOSE. An unfavourable outcome was defined as GOSE $\leq 4$, which includes both poor functional outcome and mortality.

\section{Statistical methods}

Patient characteristics were described by means ( \pm standard deviation, SD), medians (I-III quartiles, $\mathrm{Q}_{1}-\mathrm{Q}_{3}$ ) and counts or proportions, as appropriate. The comparison of baseline features according to ICP monitoring was performed using Mann-Whitney $U$ test, $t$ test and Chi-square test as appropriate. We used the median odds ratio (MOR) to estimate the between-centre heterogeneity in targeting a $\mathrm{PaCO}_{2}$ of $35-45 \mathrm{mmHg}$. MOR was obtained from a longitudinal logistic mixed-effect model on daily lowest $\mathrm{PaCO}_{2}$ adjusted for the IMPACT core covariates [19], ICP monitoring, and daily evidence of elevated ICP (at least one ICP $>20 \mathrm{mmHg}$ during the day); and with a hierarchical random intercept effect's structure (i.e., patients within centers). The same model architecture was used to quantify between-centres heterogeneity in the use of profound HV.

We resorted to an instrumental variable approach to evaluate the association between $\mathrm{HV}$ and 6-month outcomes, trying to minimize the potential measured and unmeasured confounding acting in this complex observational study [20]. This was done by considering the propensity of centres to apply profound $\mathrm{HV}$, measured as the proportion of daily lowest $\mathrm{PaCO}_{2}<30 \mathrm{mmHg}$, as an instrument in the logistic regression model with a random intercept for centers. This model was adjusted for some subject-specific covariates that included IMPACT core covariates at baseline, ICP monitoring and dose of intracranial hypertension, calculated as the area under the ICP profile above $20 \mathrm{mmHg}$, named AUC ICP $>20[21]$. The assumptions underlying the IV approach were assessed (ESM-Statistical methods).

Tests were performed with a two-sided significance level of 5\%. All analyses were conducted using R statistical software (version 4.03).

\section{Results}

Of the 4509 patients included in the CENTER-TBI dataset, 2138 patients with TBI from 51 centers in Europe were admitted to ICU. Among these, 1176 required mechanical ventilation and had at least two $\mathrm{PaCO}_{2}$ measurements within the first 7 days from ICU admission. Excluding the centres that enrolled less than ten patients, 1100 patients from 36 centers were available for the analysis (ESM Fig. 1). During the first week of ICU admission, a total of 11,791 measurements of $\mathrm{PaCO}_{2}$ were available (5931 lowest and 5860 highest daily values).

\section{Patient characteristics}

Patient characteristics at hospital admission in the overall population and stratified according to the presence $(n=751)$ or not $(n=349)$ of ICP monitoring, are summarized in Table 1 . The median age was 48 years (Q1$\mathrm{Q} 3=29-64)$, and most patients were male (74\%). 64.7\% of patients presented with a severe TBI (Glasgow Coma Scale, GCS $\leq 8$ ) and $12.5 \%$ of cases were complicated by thoracic trauma. In $727(97 \%) \mathrm{ICP}_{\mathrm{m}}$ patients, ICP was inserted by the second day of ICU admission.

In the overall population, the mean $\mathrm{PaCO}_{2}$ at ICU admission was $39.1( \pm 6) \mathrm{mmHg}$, and the no- $\mathrm{ICP}_{\mathrm{m}}$ group had higher $\mathrm{PaCO}_{2}$ mean values compared to the $\mathrm{ICP}_{\mathrm{m}}$ patients $(39.9 \pm 6.8$ vs $38.7 \pm 5.6 \mathrm{mmHg}, p<0.002)$.

\section{Lowest $\mathrm{PaCO}_{2}$ targets according to centers}

Daily minimum $\mathrm{PaCO}_{2}$ distribution during the first week for the whole population, and separated by the centre, are presented in Fig. 1a. The overall mean lowest $\mathrm{PaCO}_{2}$ was $35.2 \pm 5.4 \mathrm{mmHg}$ with substantial heterogeneity between centres, whose means ranged from $32.3( \pm 3.7)$ to $38.7 \mathrm{mmHg}( \pm 5.9)$. This result seems to be related more to different management strategies at the centre level, rather than reflecting national policies (Fig. 1b). For example, among the UK centers (in yellow), two centers had a mean $\mathrm{PaCO}_{2}$ value of 32.3 and $36.4 \mathrm{mmHg}$.

Only $144(13 \%)$ patients had all $\mathrm{PaCO}_{2}$ measurements between 35 and $45 \mathrm{mmHg}$, while 588 (53\%) patients had at least half of the total $\mathrm{PaCO}_{2}$ measurements in this range. Using MOR to quantify between-centre differences in targeting the suggested $\mathrm{PaCO}_{2}$ range of $35-45 \mathrm{mmHg}$, we found that, after correction for patient and trauma characteristics, there was a 1.72-fold difference in the odds of having a $\mathrm{PaCO}_{2}$ range of $35-45 \mathrm{mmHg}$ between centres with the highest and lowest rates. After excluding 390 patients with intracranial hypertension, the percentage of patients with all and at least half of the total $\mathrm{PaCO}_{2}$ measurements between 35 and $45 \mathrm{mmHg}$ raised to $19 \%$ $(111 / 593)$ and $64 \%$ (380/593), while MOR decreased to 1.4 . 
$\approx \mathrm{AT} \approx \mathrm{BE} \approx \mathrm{DE} \approx \mathrm{ES} \approx \mathrm{FI} \approx \mathrm{FR} \approx \mathrm{HU} \approx \mathrm{IT} \approx \mathrm{LT} \approx \mathrm{NL} \approx \mathrm{NO} \approx \mathrm{SE} \approx \mathrm{UK}$

a

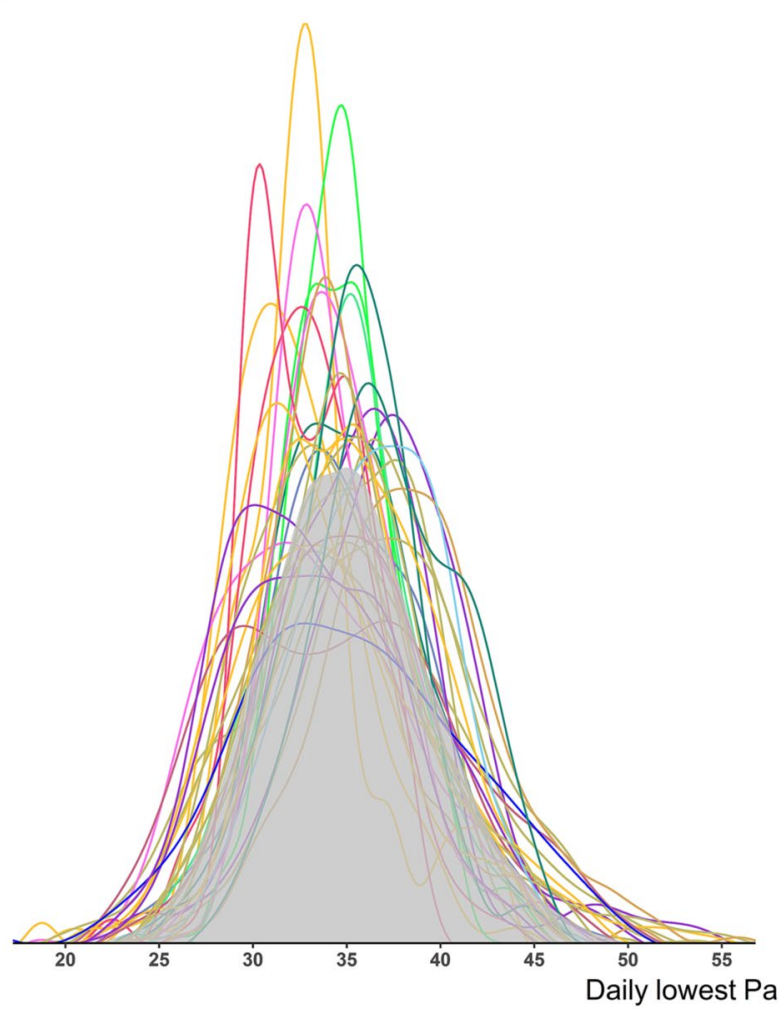

b

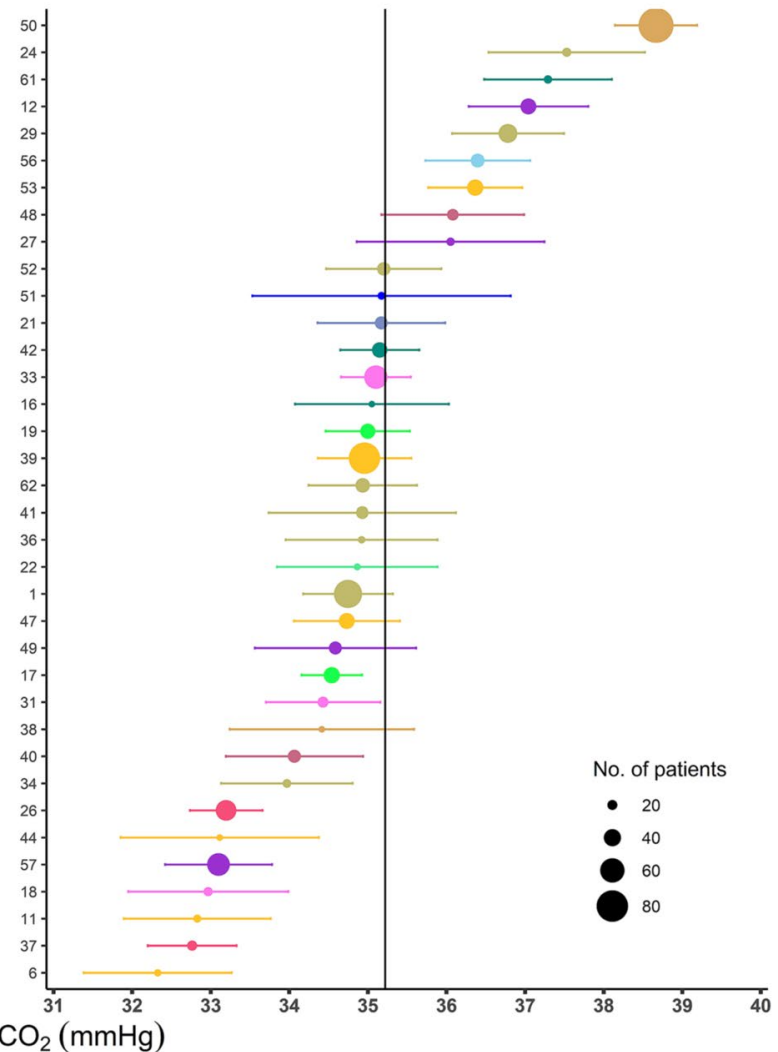

Fig. 1 (a) Distributions of the daily lowest $\mathrm{PaCO}_{2}$ recorded in the first 7 days of ICU in each participating centre (coloured by country) and overall (grey area). These distributions were estimated by a Gaussian kernel density. (b) Centre-specific mean values (coloured by country) of daily lowest $\mathrm{PaCO}_{2}$ with the corresponding 95\% confidence intervals. The solid vertical line represents the overall mean of daily lowest PaCO $\mathrm{Ca}_{2}$ values, and the size of the dots is proportional to the number of patients in the centre. $\mathrm{PaCO}_{2}$ the partial pressure of carbon dioxide, AT Austria, BE Belgium, DE Germany, ES Spain, FI Finland, FR France, HU Hungary, IT Italy, LT Lithuania, NL Netherlands, NO Norway, SE Serbia, UK United Kingdom

\section{Lowest $\mathrm{PaCO}_{2}$ targets in the presence or not of ICP monitoring}

Mean minimum $\mathrm{PaCO}_{2}$ values were significantly lower in $\mathrm{ICP}_{\mathrm{m}}$ patients compared to no- $\mathrm{ICP}_{\mathrm{m}}(34.7 \pm 4.9 \mathrm{mmHg}$ vs $36.8 \pm 5.7 \mathrm{mmHg}, p<0.001)$. Large variability was observed among centers in the management of $\mathrm{PaCO}_{2}$ targets in both subgroups (Fig. 2 and ESM Fig. 2). Some centres showed no differences in target $\mathrm{PaCO}_{2}$ when $\mathrm{ICP}_{\mathrm{m}}$ was used (i.e. data points near the line of identity in Fig. 2a), but most hospitals tended to adopt lower $\mathrm{PaCO}_{2}$ targets when ICP was monitored (i.e. data points that deviate substantially from the line of identity in Fig. 2a). For example, three centers showed a reduction greater than $4 \mathrm{mmHg}$ in the mean daily lowest $\mathrm{PaCO}_{2}$ when ICP monitoring was available (from $38-38.4 \mathrm{mmHg}$ to 33.1-34.2 $\mathrm{mmHg}$ ).
Lowest $\mathrm{PaCO}_{2}$ in the presence of intracranial hypertension In the subgroup of patients with ICP monitoring, we also explored the attitude of centres in response to episodes of intracranial hypertension $(n=3646)$. Some centres showed no differences in target $\mathrm{PaCO}_{2}$ when ICP was elevated (i.e. data points near the line of identity in Fig. 2b), but most hospitals tended to adopt lower $\mathrm{PaCO}_{2}$ targets when ICP was monitored (i.e. data points that deviate substantially from the line of identity in Fig. 2b). The mean minimum $\mathrm{PaCO}_{2}$ was significantly lower in 398 patients with at least one episode of intracranial hypertension compared to the 240 who did not experience increased ICP (34.1 vs $35.6 \mathrm{mmHg}, p<0.001)$. Within the group of patients with ICP monitoring in place, significant inter-centre differences were observed in the mean lowest $\mathrm{PaCO}_{2}$, both in the absence and presence of intracranial hypertension (ESM Fig. 3). 
Table 1 Baseline demographic and clinical characteristics, including trauma characteristics, clinical presentation, and neuroimaging features at ICU admission in the overall population and stratified according to the presence or not of ICP monitoring

\begin{tabular}{|c|c|c|c|c|c|}
\hline \multicolumn{2}{|l|}{ Characteristic } & \multirow{2}{*}{$\begin{array}{l}\text { Overall }(n=1100) \\
48(29-64)\end{array}$} & \multirow{2}{*}{$\begin{array}{l}\text { no-ICP } \\
53(31-69)\end{array}$} & \multirow{2}{*}{$\begin{array}{l}I_{\mathrm{m}}(n=751) \\
46(28-61)\end{array}$} & \multirow{2}{*}{$\begin{array}{l}\text { P value } \\
<0.001\end{array}$} \\
\hline Age (years), median (Q1-Q3) & & & & & \\
\hline Sex, $n(\%)$ & Female & $284(25.8)$ & $89(25.5)$ & $195(26)$ & 0.929 \\
\hline Thoracic trauma, $n(\%)$ & Yes & $138(12.5)$ & $42(12)$ & $96(12.8)$ & 0.802 \\
\hline ISS, median (Q1-Q3) & & $34(25-48)$ & $34(25-43)$ & $34(25-48)$ & 0.011 \\
\hline \multirow[t]{2}{*}{ Hypotension, n (\%) } & Yes & $178(17.4)$ & $60(17.7)$ & $118(17.3)$ & 0.936 \\
\hline & Not available & 78 & 10 & 68 & \\
\hline \multirow[t]{2}{*}{ Hypoxia, $n(\%)$} & Yes & $182(17.9)$ & $53(15.6)$ & $129(19)$ & 0.217 \\
\hline & Not available & 82 & 10 & 72 & \\
\hline \multirow[t]{3}{*}{ Severity TBI, n (\%) } & $\mathrm{GCS} \leq 8$ & $367(35.3)$ & $147(44.3)$ & $220(31)$ & $<0.001$ \\
\hline & $\mathrm{GCS}>8$ & $674(64.7)$ & $185(55.7)$ & $489(69)$ & \\
\hline & Not available & 59 & 17 & 42 & \\
\hline \multirow[t]{4}{*}{ Pupillary reactivity, n (\%) } & Both reactive & 799 (75.8) & $280(82.8)$ & $519(72.5)$ & 0.001 \\
\hline & One reactive & $89(8.4)$ & $22(6.5)$ & $67(9.4)$ & \\
\hline & Both unreactive & $166(15.7)$ & $36(10.7)$ & $130(18.2)$ & \\
\hline & Not available & 47 & 11 & 35 & \\
\hline \multirow[t]{6}{*}{ GCS motor, $n(\%)$} & None & $460(42.7)$ & $129(37.7)$ & $331(45)$ & $<0.001$ \\
\hline & Extension & $51(4.7)$ & $9(2.6)$ & $42(5.7)$ & \\
\hline & Abnormal flexion & $60(5.6)$ & $10(2.9)$ & $50(6.8)$ & \\
\hline & Normal flexion & $89(8.3)$ & $30(8.8)$ & $59(8)$ & \\
\hline & Localizes/obeys & $418(38.8)$ & $164(48)$ & $254(34.5)$ & \\
\hline & Not available & 22 & 7 & 15 & \\
\hline \multirow[t]{7}{*}{ Marshall CT classification, n (\%) } & 1 & $63(6.5)$ & $48(15.6)$ & $15(2.3)$ & 0.0005 \\
\hline & 2 & $416(42.9)$ & $167(54.2)$ & $249(37.7)$ & \\
\hline & 3 & $98(10.1)$ & $17(5.5)$ & $81(12.3)$ & \\
\hline & 4 & $19(2)$ & $3(1)$ & $16(2.4)$ & \\
\hline & 5 & $6(0.6)$ & $2(0.6)$ & $4(0.6)$ & \\
\hline & 6 & $367(37.9)$ & $71(23.1)$ & $296(44.8)$ & \\
\hline & Not available & 131 & 41 & 90 & \\
\hline Overall $\mathrm{PaCO}_{2}(\mathrm{mmHg})$, mean $(\mathrm{SD})$ & & $39.10(6)$ & $39.93(6.8)$ & $38.72(5.6)$ & 0.002 \\
\hline Lowest $\mathrm{PaCO}_{2}(\mathrm{mmHg})$, mean (SD) & & $34.66(5.98)$ & $35.92(6.67)$ & $34.09(5.56)$ & $<0.001$ \\
\hline Highest $\mathrm{PaCO}_{2}(\mathrm{mmHg})$, mean (SD) & & $43.68(8.1)$ & $44.07(8.6)$ & $43,5(7.86)$ & 0.287 \\
\hline
\end{tabular}

Hypotension was defined as a documented systolic blood pressure $<90 \mathrm{mmHg}$; hypoxia was defined as a documented partial pressure of oxygen $\left(\mathrm{PaO}_{2}\right)<8 \mathrm{kPa}$ $(60 \mathrm{mmHg})$, oxygen saturation $\left(\mathrm{SaO}_{2}\right)<90 \%$, or both; $\mathrm{PaCO}_{2}$ data refer to values at ICU admission

$\mathrm{PaCO}_{2}$ the partial pressure of carbon dioxide, SD standard deviation, Q1-Q3 I and III quartiles, ISS injury severity score, TBI traumatic brain injury, GCS Glasgow Coma Scale, $I C P_{m}$ intracranial pressure monitored, $I C U$ intensive care unit

\section{Profound hyperventilation}

An episode of profound $\mathrm{HV}\left(\mathrm{PaCO}_{2}<30 \mathrm{mmHg}\right)$ was recorded on 727 occasions during the first week of ICU admission in 397 (36\%) patients (57\% had one, 22\% two and $10 \%$ three occurrences). Results from the longitudinal mixed-effects model show notable heterogeneity between centres on the use of HV, even after adjusting for patient and trauma characteristics, with a MOR of 2.04 (Fig. 3, ESM Table 1). We found a significant positive association between the occurrence of increased ICP and the use of HV. Among $\mathrm{ICP}_{\mathrm{m}}$ patients, even after correction for covariates, the odds of HV in a day with elevated ICP was nearly three times that in a day with controlled ICP $(\mathrm{OR}=4.3495 \% \mathrm{CI}=4.25-4.44$, $p$ value $<0.0001$ vs $\mathrm{OR}=1.4795 \% \mathrm{CI}=0.97-2.22, p$ value $=0.03167)$. Finally, HV was less applied from day 1 to 7 (OR of $\mathrm{HV}$ per day $=0.83$; $95 \% \mathrm{CI}=0.82-0.84, p$ value $<0.0001)$.

\section{Neuromonitoring}

Indirect CBF monitoring, using jugular bulb venous oxygen saturation or brain tissue oxygenation, was not 
$\approx \mathrm{AT} \approx \mathrm{BE} \approx \mathrm{DE} \approx \mathrm{ES} \approx \mathrm{FI} \approx \mathrm{FR} \approx \mathrm{HU} \approx \mathrm{IT} \approx \mathrm{LT} \approx \mathrm{NL} \approx \mathrm{NO} \approx \mathrm{SE} \approx \mathrm{UK}$
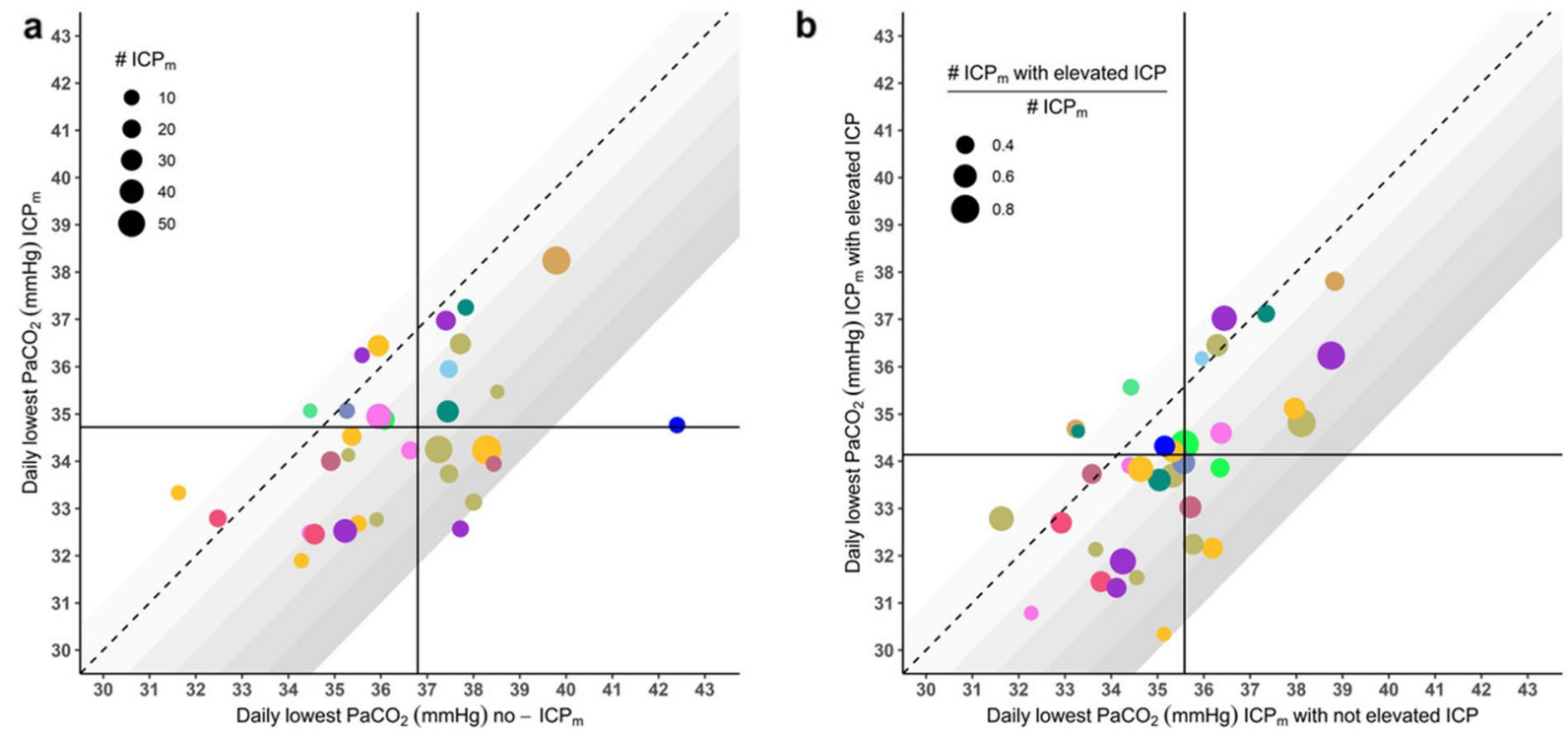

Fig. 2 (a): Scatterplot of the mean daily lowest $\mathrm{PaCO}_{2}$ values in no-ICP $\mathrm{m} v \mathrm{ICP}$ patients in each participating centre (coloured by country). The dashed line represents the line of identity, and a data point on or close to the line indicates that $\mathrm{PaCO}_{2}$ targets in that centre were not affected by the presence of ICP monitoring. The gradient of grey zones on either side of the grey area indicates increasing deviations from this line of identity between values in no-ICP $\mathrm{vs} I C P_{m}$ patients. Each gradation in shade representing one unit change $(\mathrm{mmHg})$. The size of the dots is proportional to the number of ICP $m$ patients at a centre. The outlier centre from Hungary included only two no-ICP $m$ patients, out of a total of 12 patients, with only two measurements each before ending ventilation. (b) Mean of the daily lowest $\mathrm{PaCO}_{2}$ values in ICP $\mathrm{m}$ patients with no episodes of elevated ICP (ICP $\leq 20 \mathrm{mmHg}$ ) vs ICP $\mathrm{m}$ patients with at least one episode of elevated ICP (> $20 \mathrm{mmHg}$ ) in each participating centre (coloured by country). The dashed line represents the line of identity, and the size of the dot is proportional to the number of ICP $m$ patients with elevated ICP. PaCO the partial pressure of carbon dioxide, AT Austria, BE Belgium, DE Germany, ES Spain, FI Finland, FR France, HU Hungary, IT Italy, LT Lithuania, NL Netherlands, NO Norway, SE Serbia, UK United Kingdom

used frequently. No differences were found in their use in patients receiving profoundly $\mathrm{HV}$ (jugular bulb venous oxygen saturation, $\mathrm{SjvO}_{2}: 2.4 \%$ vs profound $\mathrm{HV} 3.5 \%, p$ value $=0.380$; brain tissue oxygenation, $\mathrm{PbtO}_{2}: 14.2 \%$ vs profound HV $13.9 \%, p$ value $=0.937$ ). However, the use of profound HV was associated with significantly higher use of more aggressive treatment, expressed as mean TIL (9.7 vs $6.3 p$ value $<0.001)$. In particular, patients who received profound hyperventilation were more likely to have decompressive surgery ( 8.6 vs $4.8, p$ value $<0.001$ ) and hyperosmolar therapy (low dose 12.7 vs $5.5, p$ value $<0.001$; high dose 16.8 vs $5.7, p$ value $<0.001$ ).

\section{6 months mortality and neurological outcome}

Overall, of the 1100 patient cohort, 165 died before ICU discharge (15\%). Of the 970 patients for whom 6-month outcomes were available, 246 (25.4\%) died, and 529 (54.5\%) experienced unfavourable functional outcomes $(\mathrm{GOSE} \leq 4)$. The 6 months mortality rate was $29 \%$ in patients who had at least one episode of profound HV and $23 \%$ in those who did not ( $p$ value $=0.045$ ), while the rates of unfavourable GOSE were $64 \%$ vs $49 \%$ in the two groups, respectively ( $p$ value $<0.001)$. The percentage of patients who received profound HV in the first seven days from admission ranged from 1 to $30 \%$ between hospitals. In the IV analysis, the propensity to apply profound $\mathrm{HV}$ (defined by the use of $\mathrm{PaCO}_{2}<30 \mathrm{mmHg}$ ) did not significantly increase mortality or unfavourable functional outcome, after adjusting for the dose of intracranial hypertension. Patients in hospitals that used $10 \%$ more profound $\mathrm{HV}$ had 1.06 higher odds of mortality compared to hospitals where profound HV was applied less often $(95 \% \mathrm{CI}=0.77-1.45, p$ value $=0.7166)$ and the OR for the same comparison was $1.12(95 \% \mathrm{CI}=0.90$ $1.38, p$ value $=0.3138$ ) for an unfavourable functional outcome (Table 2).

\section{Discussion}

The current literature is inconclusive regarding the optimal ventilatory strategy to adopt in patients with TBI and, though there is increasing caution surrounding the use of $\mathrm{HV}$, the translation of expert consensus recommendations into clinical practice remains uncertain. This study examined the $\mathrm{PaCO}_{2}$ management during mechanical ventilation at a centre level in prospectively collected 


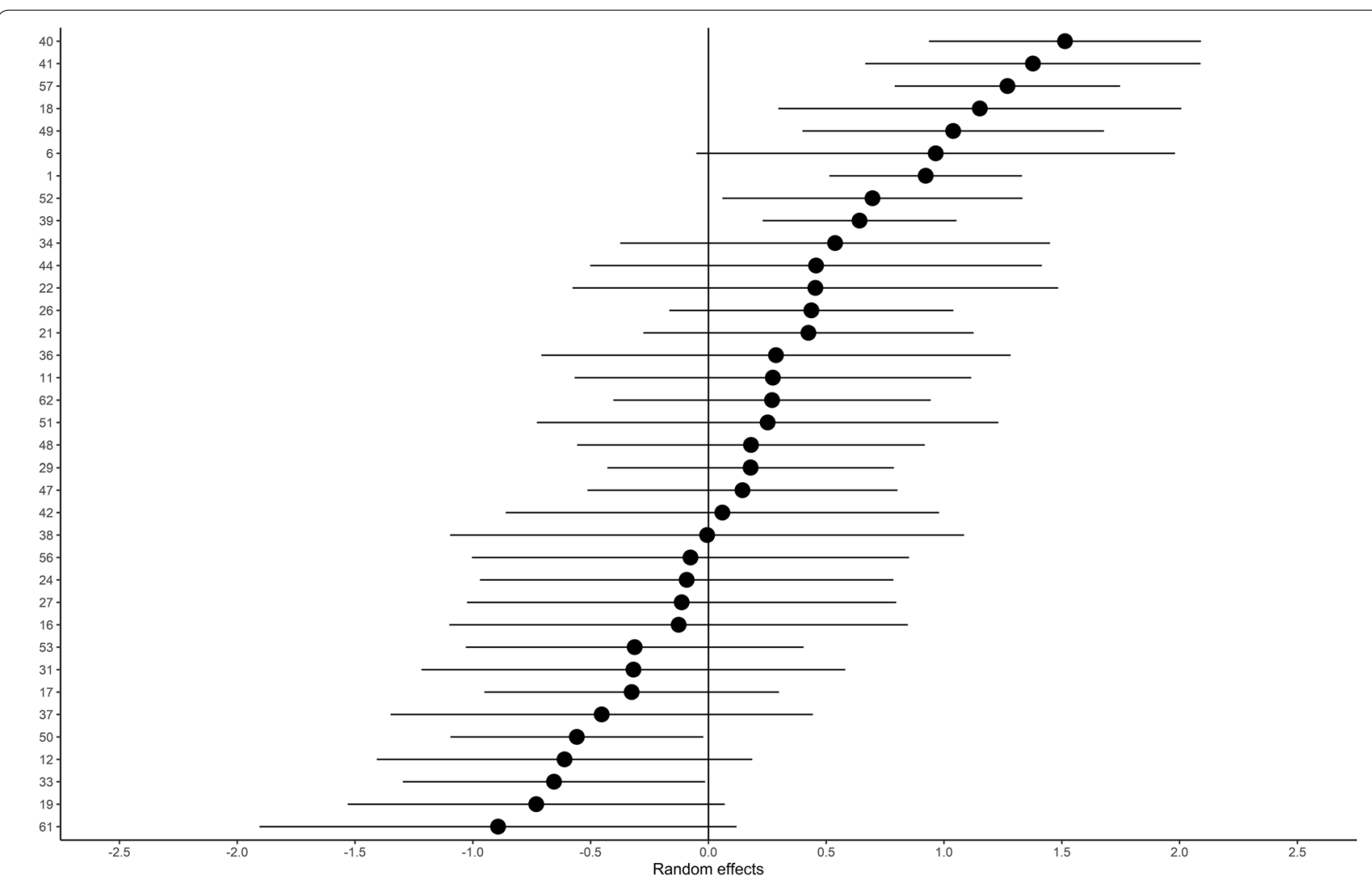

Fig. 3 Caterpillar plot of between-centre variation in using profound HV. The figure shows the predicted random intercepts for each centre, on the log-odds scale, along with their $95 \%$ prediction intervals. Higher values indicate a higher propensity to use profound HV. A longitudinal random effect logistic model was used to correct for random variation and adjusted for the core IMPACT covariates and elevated ICP. The MOR summarises the between-centre variation: a MOR $=1$ indicates no variation, while the larger the MOR is, the larger the variation present. The median odds ratio $(M O R=2.04)$ refers to the odds of using profound $\mathrm{HV}$ between two randomly selected centres for patients with the same covariates and (comparable) random effects

observational data from a large multicentre cohort of TBI patients, focusing on the use of HV.

Our main findings are:

- there is substantial practice variation among countries and centers regarding $\mathrm{PaCO}_{2}$ levels and the lowest $\mathrm{PaCO}_{2}$ adopted in TBI patients;

- patients who received ICP monitoring were managed at lower $\mathrm{PaCO}_{2}$ compared to patients in whom such monitoring was not used;

- patients who did receive ICP monitoring and experienced episodes of increased ICP were managed at lower $\mathrm{PaCO}_{2}$ levels than those who did not have ICP elevations; profound $\mathrm{HV}$ was commonly used in such patients;

- we observed no association between the risk of mortality or unfavourable functional outcome and more frequent use of profound hyperventilation $\left(\mathrm{PaCO}_{2}<30 \mathrm{mmHg}\right)$.
Appropriate management of $\mathrm{PaCO}_{2}$ is a critical requirement in mechanically ventilated patients with TBI, since carbon dioxide is one of the major determinants of cerebral vascular physiology, and therefore cerebral blood flow and volume. The effect of the interplay between carbon dioxide and perfusion pressure on the cerebral circulation results in a sophisticated modulation of cerebrovascular resistance and tone, with hypercapnia causing cerebral vasodilation, and hypocapnia, vasoconstriction.

The only randomized controlled trial [22] addressing the benefit of prophylactic hyperventilation was conducted thirty years ago, and randomised TBI patients into three categories: control $(n=41)$, hyperventilation $(n=36)$, and $\mathrm{HV}+$ tromethamine $\left(\right.$ an $\mathrm{H}^{+}$acceptor used to treat metabolic acidosis; $n=36$ ). This setting is different from the current context, as the putatively normoventilated controls had $\mathrm{PaCO}_{2}$ values in the hypocapnic range $(35 \mathrm{mmHg}$ ), and the $\mathrm{HV}$ utilized was 
Table 2 Results of the logistic mixed-effect model on 6-month outcomes by the instrumental variable approach with complete data $(n=919)$

\begin{tabular}{|c|c|c|}
\hline Outcome & $\begin{array}{l}\text { 6-month GOSE } \\
\text { OR }(95 \% \mathrm{Cl}) p \text { value }\end{array}$ & $\begin{array}{l}\text { 6-month mortality } \\
\text { OR }(95 \% \mathrm{CI}) p \text { value }\end{array}$ \\
\hline Centre HV tendency (per 10\% change)* & $1.12(0.9-1.38) 0.3138$ & $1.06(0.77-1.45) 0.7166$ \\
\hline Age & $1.04(1.03-1.05)<0.0001$ & $1.05(1.04-1.06)<0.0001$ \\
\hline \multicolumn{3}{|l|}{ GCS Motor Score } \\
\hline None & $2.08(1.46-2.95)<0.0001$ & $2.28(1.44-3.62) 0.0004$ \\
\hline Extension & $5.47(2.39-12.51)<0.0001$ & $1.82(0.74-4.48) 0.1886$ \\
\hline Abnormal flexion & $3.29(1.63-6.65) 0.0009$ & $1.69(0.65-4.37) 0.2794$ \\
\hline Normal flexion & $1.45(0.82-2.56) 0.1980$ & $1.2(0.55-2.64) 0.6421$ \\
\hline Localizes/obeys & 1 & 1 \\
\hline \multicolumn{3}{|l|}{ Pupilar reactivity } \\
\hline Both reacting & 1 & 1 \\
\hline One reacting & $1.98(1.14-3.43) 0.0146$ & $2.18(1.16-4.11) 0.0154$ \\
\hline Both unreacting & $3.29(2.05-5.27)<0.0001$ & $6.04(3.69-9.87)<0.0001$ \\
\hline \multicolumn{3}{|l|}{ ICP monitoring } \\
\hline No & 1 & 1 \\
\hline Yes & $1.79(1.27-2.51) 0.0008$ & $1.00(0.65-1.54) 0.9948$ \\
\hline AUC ICP > 20 (per one SD change) $^{\circ}$ & $3.72(1.94-7.15)<0.0001$ & $5.15(2.86-9.25)<0.0001$ \\
\hline
\end{tabular}

OR Odds ratio, $\mathrm{Cl}$ confidence intervals, SD standard deviation

* Centre HV propensity is calculated as the percentage of daily lowest $\mathrm{PaCO}_{2}<30 \mathrm{mmHg}$ out of all available measures

${ }^{\circ}$ Standardized AUC ICP $>20$ is the dose of intracranial hypertension calculated as the area under the ICP profile above $20 \mathrm{mmHg}$

profound $\left(\mathrm{PaCO}_{2} 25 \mathrm{mmHg}\right)$. These discordances with current practice, the limited number of patients, and the low incidence of episodes of intracranial hypertension make the results difficult to interpret.

A recent consensus still recommends targeting a normal range of $\mathrm{PaCO}_{2}$ values in the absence of increased ICP [12]. However, in the case of increased ICP, no agreement was achieved regarding the role of $\mathrm{HV}$, providing evidence of the current uncertainty in this area [12]. Although induced hypocapnia is considered an efficient second line measure to reduce ICP, clinicians remain worried about potential cerebral ischemic complications of hyperventilation $[8,23]$. Coles et al. used positron emission tomography in a cohort of 30 patients to show that the acute application of $\mathrm{HV}$ resulted in a reduction of cerebral blood flow and an increase in oxygen extraction fraction and the ischemic brain volume [23]. These results have left an indelible imprint on the way HV is perceived by intensivists, but they do not represent a randomized trial. Other authors suggest that mild HV may reduce ICP without leading to pathological changes of brain metabolism and oxygenation measured through cerebral microdialysis and $\mathrm{PbtO}_{2}$ [24] or energy failure. Moreover, Diringer et al. demonstrated that HV reduces global cerebral blood flow while increased oxygen extraction fraction leaving cerebral metabolic rate for oxygen unchanged, concluding that it is unlikely that HV causes neurological injury $[25,26]$.

Although some concerns still exist, $\mathrm{PaCO}_{2}$ reduction is still widely used in the clinical setting for ICP control. The most common $\mathrm{PaCO}_{2}$ target declared by clinicians in the absence of intracranial hypertension $(35-40 \mathrm{mmHg})$ is higher than in the case of raised ICP $(30-35 \mathrm{mmHg})$ [9]. Similarly, in a retrospective study of 151 patients with TBI, the $\mathrm{PaCO}_{2}$ target adopted in clinically stable ICP was $36 \pm 5.7 \mathrm{mmHg}$, whereas in the case of increased ICP it was $34 \pm 5.4 \mathrm{mmHg}$ [27]. Besides, a recent consensus on ICP treatment suggested considering $\mathrm{HV}$ to $\mathrm{PaCO}_{2}$ of $30-32 \mathrm{mmHg}$ when ICP is elevated in patients not responding to Tier 1 and 2 treatment [13].

Our data document a divergence between suggestions from literature and practice: nearly half of the daily lowest $\mathrm{PaCO}_{2}$ measurements in the first week were $<35 \mathrm{mmHg}$. Moreover, in presence of ICP monitoring, clinicians use a lower target of $\mathrm{PaCO}_{2}$. However, we also saw wide variability in $\mathrm{PaCO}_{2}$ levels between centres, both in terms of the overall values, and the lowest levels of $\mathrm{PaCO}_{2}$ observed. These differences were seen not just across the whole study cohort, but also in subgroups of patients with and without ICP monitoring, and those with and without episodes of intracranial hypertension in the first week. HV in presence of high ICP was frequently used, 
particularly in the first few days after admission, and was often combined with other ICP-lowering therapies such as osmotic agents and decompressive craniectomy. Interestingly, centres that used HV more frequently were not more likely to routinely apply more advanced neuromonitoring techniques for early detection of impaired cerebral blood flow and cerebral oxygen availability.

There is no strong evidence regarding the possible benefits or harms of profound HV on patient outcomes. However, a single retrospective analysis of 251 braininjured patients [28] reported that, when compared to controls, patients who underwent prolonged $\mathrm{HV}\left(\mathrm{PaCO}_{2}\right.$ : $25-30 \mathrm{mmHg}$; mean duration $=10, \min -\max =5-41 \mathrm{~h}$ ) experienced lower mortality ( 9.8 vs. $32.8 \%$ ) but a higher rate of poor functional outcome.

We found that being treated in a centre where profound hypocapnia is more frequently used compared to centers where it is rarely used was not significantly associated with a higher rate of mortality or poor functional outcome.

In summary, our results suggest that moderate HV is widely used in severely brain-injured patients, especially when ICP is monitored, and in case of elevated ICP.

\section{Limitations}

Although our results may provide useful context with an important clinical message for physicians, we believe they should be interpreted with caution for several reasons. First, 6 months GOSE and mortality are influenced by several other factors, such as systemic and ICU complications, as well as post-ICU events. Therefore, based on observational data, it is speculative to draw a direct causal relationship between $\mathrm{PaCO}_{2}$ and outcome: further randomized controlled studies are needed to assess the effect of $\mathrm{PaCO}_{2}$ more precisely and in particular $\mathrm{HV}$, on the outcome. Second, this is an analysis of data from a large study, which primarily addressed the epidemiology, clinical care and outcome of TBI. However, as respiratory management was not a primary focus of the study, more specific data on ventilatory management of these patients are missing, and hence unavailable to strengthen our analysis. Data on the incidence and timing of pulmonary complications such as acute respiratory distress respiratory syndrome and ventilator-associated pneumonia, the use of ventilatory strategies used to manipulate $\mathrm{PaCO}_{2}$, and the ventilator settings used in our study population are unavailable. Third, the outcome was evaluated at 6 months, which can be considered as an early measurement of outcome after TBI, and further long-term evaluations would have been desirable. Fourth, we did not specifically take into consideration the temperature management of the patients, which can importantly affect $\mathrm{PaCO}_{2}$ values. However, the measurements of $\mathrm{PaCO}_{2}$ are automatically corrected for temperature from the arterial blood gases machines, and we aimed to assess the targets of $\mathrm{PaCO}_{2}$ achieved, regardless of the effects of different factors on its final value.

Finally, in our dataset only the daily lowest and highest $\mathrm{PaCO}_{2}$ values were collected, thus missing possible changes in $\mathrm{PaCO}_{2}$ and pulmonary function parameters that may occur suddenly and repeatedly during the day. However, our analysis includes data on daily $\mathrm{PaCO}_{2}$, thus providing a longitudinal view of $\mathrm{PaCO}_{2}$ management over time.

\section{Conclusions}

In a large cohort of mechanically ventilated TBI patients, we found substantial between-centre variations in $\mathrm{PaCO}_{2}$, but with a large proportion of patients being managed at $\mathrm{PaCO}_{2}$ levels below those suggested by expert consensus statements. On average, patients who had ICP monitors in place had significantly lower $\mathrm{PaCO}_{2}$ levels than those that did not, and amongst ICP monitored patients, $\mathrm{PaCO}_{2}$ levels were lower in patients who had episodes of intracranial hypertension-suggesting that $\mathrm{HV}$ is still used for ICP management. Profound hyperventilation $\left(\mathrm{PaCO}_{2}<30 \mathrm{mmHg}\right)$ was not uncommon. However, a centre that had a greater propensity to use profound $\mathrm{HV}$ did not worsen 6-month mortality or functional outcome. Notwithstanding this, we believe that the available evidence still makes the case for caution in the use of $\mathrm{HV}$, with careful consideration of risks and benefits on a caseby-case basis. Our data provide no basis for dismissing continuing concerns regarding prophylactic or profound hyperventilation. We need randomized controlled trials and high-level evidence guidelines to support rational choices regarding optimal ventilation management and $\mathrm{PaCO}_{2}$ targets in patients with TBI.

\section{Supplementary Information}

The online version contains supplementary material available at https://doi. org/10.1007/s00134-021-06470-7.

\begin{abstract}
Abbreviations
AUC CO 2 i: Area below the value of $30 \mathrm{mmHg}$ as a benchmark and the interpolation of the $\mathrm{PaCO}_{2}$ profile in time; AUC ICP > 20: Area under ICP profile above $20 \mathrm{mmHg}$; CBF: Cerebral blood flow; CENTER-TBI: Collaborative European NeuroTrauma Effectiveness Research in Traumatic Brain Injury; Cl: Confidence interval; $\mathrm{CO}_{2}$ : Carbon dioxide; $\mathrm{CT}$ : Computed tomography; ESM: Electronic supplementary material; GCS: Glasgow coma scale; GOSE: Glasgow outcome scale extended; HP: Hypocapnia; HR: Hazard rate; HV: Hyperventilation; ICP:

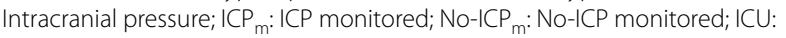
Intensive care unit; ISS: Injury severity score; LOS: Length of stay; MOR: Median odds ratio; $\mathrm{OR}$ : Odds ratio; $\mathrm{PaCO}_{2}$ : Partial pressure of carbon dioxide; $\mathrm{PbtO}_{2}$ : Brain tissue oxygenation; $\mathrm{SaO}_{2}$ : Oxygen saturation; $\mathrm{SjvO}_{2}$ : Jugular bulb venous oxygen saturation; SD: Standard deviation; STROBE: Strengthening the Reporting of Observational Studies in Epidemiology; TBI: Traumatic brain injury; TLL: Therapy intensity level.
\end{abstract}

\footnotetext{
Author details

${ }^{1}$ School of Medicine and Surgery, University of Milano - Bicocca, Monza, Italy. ${ }^{2}$ Neurointensive Care Unit, Ospedale San Gerardo, Azienda Socio-Sanitaria
} 
Territoriale Di Monza, Monza, Italy. ${ }^{3}$ Anesthesia and Intensive Care, Policlinico San Martino, IRCCS for Oncology and Neuroscience, Genoa, Italy. ${ }^{4}$ Department of Surgical Science and Integrated Diagnostic, University of Genoa, Genoa, Italy. ${ }^{5}$ Bicocca Bioinformatics Biostatistics and Bioimaging Center B4, School of Medicine and Surgery, University of Milano - Bicocca, Milan, Italy. ${ }^{6}$ Department of Clinical-Surgical, Diagnostic and Paediatric Sciences, Unit of Anaesthesia and Intensive Care, University of Pavia, Pavia, Italy. ${ }^{7}$ Anesthesia and Intensive Care, School of Medicine, Messina, Italy. ${ }^{8}$ Fondazione IRCCS Cà Granda Ospedale Maggiore Policlinico, Milan, Italy. ${ }^{9}$ Department of Physiopathology and Transplantation, Milan University, Milan, Italy. ${ }^{10}$ Neurocritical Care Unit, Addenbrooke's Hospital, Cambridge, UK.

\section{Acknowledgements}

We acknowledge the CENTER-TBI ICU Participants and Investigators listed here as non-authors contributors: Cecilia Åkerlund' ${ }^{1}$ Krisztina Amrein², Nada Andelic ${ }^{3}$, Lasse Andreassen ${ }^{4}$, Audny Anke ${ }^{5}$, Anna Antoni ${ }^{6}$, Gérard Audibert ${ }^{7}$, Philippe Azouvi ${ }^{8}$, Maria Luisa Azzolini ${ }^{9}$, Ronald Bartels ${ }^{10}$, Pál Barzó $^{11}$, Romuald Beauvais ${ }^{12}$, Ronny Beer ${ }^{13}$, Bo-Michael Bellander ${ }^{14}$, Antonio Belli ${ }^{15}$, Habib Benali ${ }^{16}$, Maurizio Berardino ${ }^{17}$, Luigi Beretta ${ }^{9}$, Morten Blaabjerg ${ }^{18}$, Peter Bragge ${ }^{19}$, Alexandra Brazinova ${ }^{20}$, Vibeke Brinck ${ }^{21}$, Joanne Brooker $^{22}$, Camilla Brorsson ${ }^{23}$, Andras Buki ${ }^{24}$, Monika Bullinger ${ }^{25}$, Manuel Cabeleira ${ }^{26}$, Alessio Caccioppola ${ }^{27}$, Emiliana Calappi ${ }^{27}$, Maria Rosa Calvi ${ }^{9}$, Peter Cameron ${ }^{28}$, Guillermo Carbayo Lozano ${ }^{29}$, Marco Carbonara ${ }^{27}$, Simona Cavallo $^{17}$, Giorgio Chevallard ${ }^{30}$, Arturo Chieregato ${ }^{30}$, Giuseppe Citerio ${ }^{31}$ 32, Hans Clusmann ${ }^{33}$, Mark Coburn ${ }^{34}$, Jonathan Coles ${ }^{35}$, Jamie D. Cooper ${ }^{36}$, Marta Correia ${ }^{37}$, Amra Čović ${ }^{38}$, Nicola Curry ${ }^{39}$, Endre Czeiter ${ }^{24}$, Marek Czosnyka ${ }^{26}$, Claire Dahyot-Fizelier ${ }^{40}$, Paul Dark ${ }^{41}$, Helen Dawes ${ }^{42}$, Véronique De Keyser ${ }^{43}$, Vincent Degos ${ }^{16}$, Francesco Della Corte ${ }^{44}$, Hugo den Boogert ${ }^{10}$, Bart Depreitere ${ }^{45}$, Đula Đilvesi ${ }^{46}$, Abhishek Dixit ${ }^{47}$, Emma Donoghue ${ }^{22}$, Jens Dreier $^{48}$, Guy-Loup Dulière ${ }^{49}$, Ari Ercole ${ }^{47}$, Patrick Esser ${ }^{42}$, Erzsébet Ezer ${ }^{50}$, Martin Fabricius ${ }^{51}$, Valery L. Feigin ${ }^{52}$, Kelly Foks ${ }^{53}$, Shirin Frisvold ${ }^{54}$, Alex Furmanov $^{55}$, Pablo Gagliard ${ }^{56}$, Damien Galanaud ${ }^{16}$, Dashiell Gantner ${ }^{28}$, Guoyi Gao ${ }^{57}$, Pradeep George ${ }^{58}$, Alexandre Ghuysen ${ }^{59}$, Lelde Giga ${ }^{60}$, Ben Glocker $^{61}$, Jagoš Golubovic ${ }^{46}$, Pedro A. Gomez ${ }^{62}$, Johannes Gratz ${ }^{63}$, Benjamin Gravesteijn ${ }^{64}$, Francesca Grossi ${ }^{44}$, Russell L. Gruen ${ }^{65}$, Deepak Gupta ${ }^{66}$, Juanita A. Haagsma ${ }^{64}$, lain Haitsma ${ }^{67}$, Raimund Helbok ${ }^{13}$, Eirik Helseth ${ }^{68}$, Lindsay Horton ${ }^{69}$, Jilske Huijben ${ }^{64}$, Peter J. Hutchinson ${ }^{70}$, Bram Jacobs ${ }^{71}$, Stefan Jankowski ${ }^{72}$, Mike Jarrett ${ }^{21}$, Ji-yao Jiang ${ }^{58}$, Faye Johnson ${ }^{73}$, Kelly Jones ${ }^{52}$, Mladen Karan ${ }^{46}$, Angelos G. Kolias ${ }^{70}$, Erwin Kompanje ${ }^{74}$, Daniel Kondziella ${ }^{51}$, Evgenios Kornaropoulos ${ }^{47}$, Lars-Owe Koskinen ${ }^{75}$, Noémi Kovács ${ }^{76}$, Ana Kowark ${ }^{77}$, Alfonso Lagares ${ }^{62}$, Linda Lanyon ${ }^{58}$, Steven Laureys ${ }^{78}$, Fiona Lecky ${ }^{79}$, ${ }^{80}$, Didier Ledoux $x^{78}$, Rolf Lefering ${ }^{81}$, Valerie Legrand ${ }^{82}$, Aurelie Lejeune ${ }^{83}$, Leon Levi ${ }^{84}$, Roger Lightfoot ${ }^{85}$, Hester Lingsma ${ }^{64}$, Andrew I.R. Maas ${ }^{43}$, Ana M. Castaño-León ${ }^{62}$, Marc Maegele ${ }^{86}$, Marek Majdan ${ }^{20}$, Alex Manara ${ }^{87}$, Geoffrey Manley ${ }^{88}$, Costanza Martino ${ }^{89}$, Hugues Maréchal ${ }^{49}$, Julia Mattern ${ }^{90}$, Catherine McMahon ${ }^{91}$, Béla Melegh ${ }^{92}$, David Menon ${ }^{47}$, Tomas Menovsky ${ }^{43}$, Ana Mikolic ${ }^{64}$, Benoit Misset ${ }^{78}$, Visakh Muraleedharan ${ }^{58}$, Lynnette Murray ${ }^{28}$, Ancuta Negru' ${ }^{93}$, David Nelson', Virginia Newcombe ${ }^{47}$, Daan Nieboer ${ }^{64}$, József Nyirádi ${ }^{2}$, Otesile Olubukola ${ }^{79}$, Matej Oresic ${ }^{94}$, Fabrizio Ortolano ${ }^{27}$, Aarno Palotie ${ }^{95,96,97}$, Paul M. Parizel ${ }^{98}$, Jean-François Payen ${ }^{99}$, Natascha Perera ${ }^{12}$, Vincent Perlbarg ${ }^{16}$, Paolo Persona ${ }^{100}$, Wilco Peul ${ }^{101}$, Anna PiippoKarjalainen ${ }^{102}$, Matti Pirinen ${ }^{95}$, Dana Pisica ${ }^{64}$, Horia Ples ${ }^{93}$, Suzanne Polinder ${ }^{64}$, Inigo Pomposo ${ }^{29}$, Jussi P. Posti ${ }^{103}$, Louis Puybasset ${ }^{104}$, Andreea Radoi ${ }^{105}$, Arminas Ragauskas ${ }^{106}$, Rahul Raj ${ }^{102}$, Malinka Rambadagalla ${ }^{107}$, Isabel Retel Helmrich ${ }^{64}$, Jonathan Rhodes ${ }^{108}$, Sylvia Richardson ${ }^{109}$, Sophie Richter ${ }^{47}$, Samuli Ripatti ${ }^{95}$, Saulius Rocka ${ }^{106}$, Cecilie Roe ${ }^{110}$, Olav Roise ${ }^{111,112}$, Jonathan Rosand ${ }^{113}$, Jeffrey V. Rosenfeld ${ }^{114}$, Christina Rosenlund ${ }^{115}$, Guy Rosenthal ${ }^{55}$ Rolf Rossaint ${ }^{77}$, Sandra Rossi ${ }^{100}$, Daniel Rueckert ${ }^{61}$ Martin Rusnák ${ }^{116}$, Juan Sahuquillo ${ }^{105}$, Oliver Sakowitz ${ }^{\prime 0,117}$, Renan Sanchez-Porras $^{117}$, Janos Sandor ${ }^{118}$, Nadine Schäfer ${ }^{81}$, Silke Schmidt ${ }^{119}$, Herbert Schoechl ${ }^{120}$, Guus Schoonman ${ }^{121}$, Rico Frederik Schou ${ }^{122}$, Elisabeth Schwendenwein ${ }^{6}$, Charlie Sewalt ${ }^{64}$, Toril Skandsen ${ }^{123,124}$, Peter Smielewski ${ }^{26}$, Abayomi Sorinola ${ }^{125}$, Emmanuel Stamatakis ${ }^{47}$, Simon Stanworth ${ }^{39}$, Robert Stevens ${ }^{126}$, William Stewart ${ }^{127}$, Ewout W. Steyerberg ${ }^{64,} 128$, Nino Stocchetti ${ }^{129}$, Nina Sundström ${ }^{130}$, Riikka Takala ${ }^{131}$, Viktória Tamás ${ }^{125}$, Tomas Tamosuitis ${ }^{132}$, Mark Steven Taylor ${ }^{20}$, Braden Te Ao ${ }^{52}$, Olli Tenovuo ${ }^{103}$, Alice Theadom ${ }^{52}$, Matt Thomas $^{87}$, Dick Tibboel ${ }^{133}$, Marjolein Timmers ${ }^{74}$, Christos Tolias ${ }^{134}$, Tony Trapani ${ }^{28}$, Cristina Maria Tudora ${ }^{93}$, Andreas Unterberg ${ }^{90}$, Peter Vajkoczy ${ }^{135}$, Shirley Vallance ${ }^{28}$, Egils Valeinis ${ }^{60}$, Zoltán Vámos ${ }^{50}$, Mathieu van der Jagt ${ }^{136}$, Gregory Van der Steen ${ }^{43}$, Joukje van der Naalt ${ }^{71}$, Jeroen T.J.M. van Dijck 101, Thomas A. van Essen ${ }^{101}$, Wim Van Hecke ${ }^{137}$, Carolinevan Heugten ${ }^{138}$,
Dominique Van Praag ${ }^{139}$, Ernest van Veen ${ }^{64}$, Thijs Vande Vyvere ${ }^{137}$, Roel P. J. van Wijk ${ }^{101}$, Alessia Vargiolu ${ }^{32}$, Emmanuel Vega ${ }^{83}$, Kimberley Velt ${ }^{64}$, Jan Verheyden ${ }^{137}$, Paul M. Vespa ${ }^{140}$, Anne Vik ${ }^{123,}{ }^{141}$, Rimantas Vilcinis ${ }^{132}$, Victor Volovici ${ }^{67}$, Nicole von Steinbüchel ${ }^{38}$, Daphne Voormolen ${ }^{64}$, Petar Vulekovic ${ }^{46}$, Kevin K.W. Wang ${ }^{142}$, Eveline Wiegers ${ }^{64}$, Guy Williams ${ }^{47}$, Lindsay Wilson ${ }^{69}$, Stefan Winzeck $^{47}$, Stefan Wolf $f^{143}$, Zhihui Yang ${ }^{113}$, Peter Ylén ${ }^{144}$, Alexander Younsi ${ }^{90}$, Frederick A. Zeiler ${ }^{47,145}$, Veronika Zelinkova ${ }^{20}$, Agate Ziverte $^{60}$, Tommaso Zoerle ${ }^{27}$

'Department of Physiology and Pharmacology, Section of Perioperative Medicine and Intensive Care, Karolinska Institutet, Stockholm, Sweden

${ }_{2}^{2}$ János Szentágothai Research Centre, University of Pécs, Pécs, Hungary

${ }^{3}$ Division of Surgery and Clinical Neuroscience, Department of Physical

Medicine and Rehabilitation, Oslo University Hospital and University of Oslo,

Oslo, Norway

${ }^{4}$ Department of Neurosurgery, University Hospital Northern Norway,

Tromso, Norway

${ }^{5}$ Department of Physical Medicine and Rehabilitation, University Hospital Northern Norway, Tromso, Norway

${ }^{6}$ Trauma Surgery, Medical University Vienna, Vienna, Austria

${ }^{7}$ Department of Anesthesiology \& Intensive Care, University Hospital Nancy,

Nancy, France

${ }^{8}$ Raymond Poincare hospital, Assistance Publique - Hopitaux de Paris, Paris, France

${ }^{9}$ Department of Anesthesiology \& Intensive Care, S Raffaele University

Hospital, Milan, Italy

${ }^{10}$ Department of Neurosurgery, Radboud University Medical Center,

Nijmegen, The Netherlands

${ }^{11}$ Department of Neurosurgery, University of Szeged, Szeged, Hungary

${ }^{12}$ International Projects Management, ARTTIC, Munchen, Germany

${ }^{13}$ Department of Neurology, Neurological Intensive Care Unit, Medical University of Innsbruck, Innsbruck, Austria

${ }^{14}$ Department of Neurosurgery \& Anesthesia \& intensive care medicine, Karolinska University Hospital, Stockholm, Sweden

${ }^{15} \mathrm{NIHR}$ Surgical Reconstruction and Microbiology Research Centre, Birmingham, UK

${ }^{16}$ Anesthesie-Réanimation, Assistance Publique - Hopitaux de Paris, Paris, France

${ }^{17}$ Department of Anesthesia \& ICU, AOU Città della Salute e della Scienza di

Torino_-Orthopedic and Trauma Center, Torino, Italy

${ }^{18}$ Department of Neurology, Odense University Hospital, Odense, Denmark

${ }^{19}$ BehaviourWorks Australia, Monash Sustainability Institute, Monash University, Victoria, Australia

${ }^{20}$ Department of Public Health, Faculty of Health Sciences and Social Work, Trnava University, Trnava, Slovakia

${ }^{21}$ Quesgen Systems Inc., Burlingame, California, USA

${ }^{22}$ Australian \& New Zealand Intensive Care Research Centre, Department of Epidemiology and Preventive Medicine, School of Public Health and Preventive Medicine, Monash University, Melbourne, Australia

${ }^{23}$ Department of Surgery and Perioperative Science, Umeå University, Umeå, Sweden

${ }^{24}$ Department of Neurosurgery, Medical School, University of Pécs, Hungary and Neurotrauma Research Group, János Szentágothai Research Centre, University of Pécs, Hungary

${ }^{25}$ Department of Medical Psychology, Universitätsklinikum HamburgEppendorf, Hamburg, Germany

${ }^{26}$ Brain Physics Lab, Division of Neurosurgery, Dept of Clinical Neurosciences, University of Cambridge, Addenbrooke's Hospital, Cambridge, UK

${ }^{27}$ Neuro ICU, Fondazione IRCCS Cà Granda Ospedale Maggiore Policlinico, Milan, Italy

${ }^{28}$ ANZIC Research Centre, Monash University, Department of Epidemiology and Preventive Medicine, Melbourne, Victoria, Australia

${ }^{29}$ Department of Neurosurgery, Hospital of Cruces, Bilbao, Spain

${ }^{30}$ Neurolntensive Care, Niguarda Hospital, Milan, Italy

${ }^{31}$ School of Medicine and Surgery, Università Milano Bicocca, Milano, Italy

${ }^{32}$ Neurolntensive Care, ASST di Monza, Monza, Italy

${ }^{33}$ Department of Neurosurgery, Medical Faculty RWTH Aachen University, Aachen, Germany

${ }^{34}$ Department of Anesthesiology and Intensive Care Medicine, University Hospital Bonn, Bonn, Germany

${ }^{35}$ Department of Anesthesia \& Neurointensive Care, Cambridge University Hospital NHS Foundation Trust, Cambridge, UK 
${ }^{36}$ School of Public Health \& PM, Monash University and The Alfred Hospital, Melbourne, Victoria, Australia

${ }^{37}$ Radiology/MRI department, MRC Cognition and Brain Sciences Unit, Cambridge, UK

${ }^{38}$ Institute of Medical Psychology and Medical Sociology, Universitätsmedizin Göttingen, Göttingen, Germany

${ }^{39}$ Oxford University Hospitals NHS Trust, Oxford, UK

${ }^{40}$ Intensive Care Unit, CHU Poitiers, Potiers, France

${ }^{41}$ University of Manchester NIHR Biomedical Research Centre, Critical Care Directorate, Salford Royal Hospital NHS Foundation Trust, Salford, UK

${ }^{42}$ Movement Science Group, Faculty of Health and Life Sciences, Oxford Brookes University, Oxford, UK

${ }^{43}$ Department of Neurosurgery, Antwerp University Hospital and University of Antwerp, Edegem, Belgium

${ }^{44}$ Department of Anesthesia \& Intensive Care, Maggiore Della Carità Hospital, Novara, Italy

${ }^{45}$ Department of Neurosurgery, University Hospitals Leuven, Leuven, Belgium

${ }^{46}$ Department of Neurosurgery, Clinical centre of Vojvodina, Faculty of Medicine, University of Novi Sad, Novi Sad, Serbia

${ }^{47}$ Division of Anaesthesia, University of Cambridge, Addenbrooke's Hospital, Cambridge, UK

${ }^{48}$ Center for Stroke Research Berlin, Charité - Universitätsmedizin Berlin, corporate member of Freie Universität Berlin, Humboldt-Universität zu Berlin, and Berlin Institute of Health, Berlin, Germany

${ }^{49}$ Intensive Care Unit, CHR Citadelle, Liège, Belgium

${ }^{50}$ Department of Anaesthesiology and Intensive Therapy, University of Pécs, Pécs, Hungary

${ }^{51}$ Departments of Neurology, Clinical Neurophysiology and Neuroanesthesiology, Region Hovedstaden Rigshospitalet, Copenhagen, Denmark

${ }^{52}$ National Institute for Stroke and Applied Neurosciences, Faculty of Health and Environmental Studies, Auckland University of Technology, Auckland, New Zealand

${ }^{53}$ Department of Neurology, Erasmus MC, Rotterdam, the Netherlands

${ }^{54}$ Department of Anesthesiology and Intensive care, University Hospital Northern Norway, Tromso, Norway

${ }^{55}$ Department of Neurosurgery, Hadassah-hebrew University Medical center, Jerusalem, Israel

${ }^{56}$ Fundación Instituto Valenciano de Neurorrehabilitación (FIVAN), Valencia, Spain

${ }^{57}$ Department of Neurosurgery, Shanghai Renji hospital, Shanghai Jiaotong University/school of medicine, Shanghai, China

${ }^{58}$ Karolinska Institutet, INCF International Neuroinformatics Coordinating Facility, Stockholm, Sweden

${ }^{59}$ Emergency Department, CHU, Liège, Belgium

${ }^{60}$ Neurosurgery clinic,Pauls Stradins Clinical University Hospital, Riga, Latvia

${ }^{61}$ Department of Computing, Imperial College London, London, UK

${ }^{62}$ Department of Neurosurgery, Hospital Universitario 12 de Octubre, Madrid, Spain

${ }^{63}$ Department of Anesthesia, Critical Care and Pain Medicine, Medical University of Vienna, Austria

${ }^{64}$ Department of Public Health, Erasmus Medical Center-University Medical Center, Rotterdam, The Netherlands

${ }^{65}$ College of Health and Medicine, Australian National University, Canberra, Australia

${ }^{66}$ Department of Neurosurgery, Neurosciences Centre \& JPN Apex trauma centre, All India Institute of Medical Sciences, New Delhi-110029, India

${ }^{67}$ Department of Neurosurgery, Erasmus MC, Rotterdam, the Netherlands

${ }^{68}$ Department of Neurosurgery, Oslo University Hospital, Oslo, Norway

${ }^{69}$ Division of Psychology, University of Stirling, Stirling, UK

${ }^{70}$ Division of Neurosurgery, Department of Clinical Neurosciences, Addenbrooke's Hospital \& University of Cambridge, Cambridge, UK

${ }^{71}$ Department of Neurology, University of Groningen, University Medical Center Groningen, Groningen, Netherlands

${ }^{72}$ Neurointensive Care, Sheffield Teaching Hospitals NHS Foundation Trust, Sheffield, UK

${ }^{73}$ Salford Royal Hospital NHS Foundation Trust Acute Research Delivery Team, Salford, UK

${ }^{74}$ Department of Intensive Care and Department of Ethics and Philosophy of Medicine, Erasmus Medical Center, Rotterdam, The Netherlands

${ }^{75}$ Department of Clinical Neuroscience, Neurosurgery, Umeå University,
Umeå, Sweden

${ }^{76}$ Hungarian Brain Research Program—Grant No. KTIA_13_NAP-A-II/8, University of Pécs, Pécs, Hungary

${ }^{77}$ Department of Anaesthesiology, University Hospital of Aachen, Aachen, Germany

${ }^{78} \mathrm{Cyclotron}$ Research Center , University of Liège, Liège, Belgium

${ }^{79} \mathrm{Centre}$ for Urgent and Emergency Care Research (CURE), Health Services Research Section, School of Health and Related Research (ScHARR), University of Sheffield, Sheffield, UK

${ }^{80}$ Emergency Department, Salford Royal Hospital, Salford UK

${ }^{81}$ Institute of Research in Operative Medicine (IFOM), Witten/Herdecke

University, Cologne, Germany

${ }^{82} \mathrm{VP}$ Global Project Management CNS, ICON, Paris, France

${ }^{83}$ Department of Anesthesiology-Intensive Care, Lille University Hospital,

Lille, France

${ }^{84}$ Department of Neurosurgery, Rambam Medical Center, Haifa, Israel

${ }^{85}$ Department of Anesthesiology \& Intensive Care, University Hospitals Southhampton NHS Trust, Southhampton, UK

${ }^{86}$ Cologne-Merheim Medical Center (CMMC), Department of Traumatology, Orthopedic Surgery and Sportmedicine, Witten/Herdecke University, Cologne, Germany

${ }^{87}$ Intensive Care Unit, Southmead Hospital, Bristol, Bristol, UK

${ }^{88}$ Department of Neurological Surgery, University of California, San Francisco, California, USA

${ }^{89}$ Department of Anesthesia \& Intensive Care,M. Bufalini Hospital, Cesena, Italy

${ }^{90}$ Department of Neurosurgery, University Hospital Heidelberg, Heidelberg, Germany

${ }^{91}$ Department of Neurosurgery, The Walton centre NHS Foundation Trust, Liverpool, UK

${ }^{92}$ Department of Medical Genetics, University of Pécs, Pécs, Hungary

${ }^{93}$ Department of Neurosurgery, Emergency County Hospital Timisoara, Timisoara, Romania

${ }^{94}$ School of Medical Sciences, Örebro University, Örebro, Sweden

${ }^{95}$ Institute for Molecular Medicine Finland, University of Helsinki, Helsinki, Finland

${ }^{96}$ Analytic and Translational Genetics Unit, Department of Medicine; Psychiatric \& Neurodevelopmental Genetics Unit, Department of Psychiatry; Department of Neurology, Massachusetts General Hospital, Boston, MA, USA

${ }^{97}$ Program in Medical and Population Genetics; The Stanley Center for Psy-

chiatric Research, The Broad Institute of MIT and Harvard, Cambridge, MA, USA

${ }^{98}$ Department of Radiology, University of Antwerp, Edegem, Belgium

${ }^{99}$ Department of Anesthesiology \& Intensive Care, University Hospital of Grenoble, Grenoble, France

${ }^{100}$ Department of Anesthesia \& Intensive Care, Azienda Ospedaliera Università di Padova, Padova, Italy

${ }^{101}$ Dept. of Neurosurgery, Leiden University Medical Center, Leiden, The Netherlands and Dept. of Neurosurgery, Medical Center Haaglanden, The Hague, The Netherlands

${ }^{102}$ Department of Neurosurgery, Helsinki University Central Hospital

${ }^{103}$ Division of Clinical Neurosciences, Department of Neurosurgery and

Turku Brain Injury Centre, Turku University Hospital and University of Turku, Turku, Finland

${ }^{104}$ Department of Anesthesiology and Critical Care, Pitié -Salpêtrière Teaching Hospital, Assistance Publique, Hôpitaux de Paris and University Pierre et

Marie Curie, Paris, France

${ }^{105}$ Neurotraumatology and Neurosurgery Research Unit (UNINN), Vall

d'Hebron Research Institute, Barcelona, Spain

${ }^{106}$ Department of Neurosurgery, Kaunas University of technology and Vilnius University, Vilnius, Lithuania

${ }^{107}$ Department of Neurosurgery, Rezekne Hospital, Latvia

${ }^{108}$ Department of Anaesthesia, Critical Care \& Pain Medicine NHS Lothian \& University of Edinburg, Edinburgh, UK

${ }^{109}$ Director, MRC Biostatistics Unit, Cambridge Institute of Public Health, Cambridge, UK

${ }^{110}$ Department of Physical Medicine and Rehabilitation, Oslo University Hospital/University of Oslo, Oslo, Norway

${ }^{111}$ Division of Orthopedics, Oslo University Hospital, Oslo, Norway

${ }^{112}$ Institue of Clinical Medicine, Faculty of Medicine, University of Oslo, Oslo, Norway

${ }^{113}$ Broad Institute, Cambridge MA Harvard Medical School, Boston MA, Mas- 
sachusetts General Hospital, Boston MA, USA

${ }^{114}$ National Trauma Research Institute, The Alfred Hospital, Monash University, Melbourne, Victoria, Australia

${ }^{115}$ Department of Neurosurgery, Odense University Hospital, Odense, Denmark

${ }^{116}$ International Neurotrauma Research Organisation, Vienna, Austria

${ }^{117}$ Klinik für Neurochirurgie, Klinikum Ludwigsburg, Ludwigsburg, Germany

${ }^{118}$ Division of Biostatistics and Epidemiology, Department of Preventive Medicine, University of Debrecen, Debrecen, Hungary

${ }^{119}$ Department Health and Prevention, University Greifswald, Greifswald, Germany

${ }^{120}$ Department of Anaesthesiology and Intensive Care, AUVA Trauma Hospital, Salzburg, Austria

${ }^{121}$ Department of Neurology, Elisabeth-TweeSteden Ziekenhuis, Tilburg, the Netherlands

${ }^{122}$ Department of Neuroanesthesia and Neurointensive Care, Odense University Hospital, Odense, Denmark

${ }^{123}$ Department of Neuromedicine and Movement Science, Norwegian University of Science and Technology, NTNU, Trondheim, Norway

${ }^{124}$ Department of Physical Medicine and Rehabilitation, St.Olavs Hospital,

Trondheim University Hospital, Trondheim, Norway

${ }^{125}$ Department of Neurosurgery, University of Pécs, Pécs, Hungary

${ }^{126}$ Division of Neuroscience Critical Care, John Hopkins University School of Medicine, Baltimore, USA

${ }^{127}$ Department of Neuropathology, Queen Elizabeth University Hospital and University of Glasgow, Glasgow, UK

${ }^{128}$ Dept. of Department of Biomedical Data Sciences, Leiden University Medical Center, Leiden,The Netherlands

${ }^{129}$ Department of Pathophysiology and Transplantation, Milan University, and Neuroscience ICU, Fondazione IRCCS Cà Granda Ospedale Maggiore Policlinico, Milano, Italy

${ }^{130}$ Department of Radiation Sciences, Biomedical Engineering, Umeå University, Umeå, Sweden

${ }^{131}$ Perioperative Services, Intensive Care Medicine and Pain Management, Turku University Hospital and University of Turku, Turku, Finland

${ }^{132}$ Department of Neurosurgery, Kaunas University of Health Sciences, Kaunas, Lithuania

${ }^{133}$ Intensive Care and Department of Pediatric Surgery, Erasmus Medical Center, Sophia Children's Hospital, Rotterdam, The Netherlands

${ }^{134}$ Department of Neurosurgery, Kings college London, London, UK

${ }^{135}$ Neurologie, Neurochirurgie und Psychiatrie, Charité - Universitätsmedizin Berlin, Berlin, Germany

${ }^{136}$ Department of Intensive Care Adults, Erasmus MC- University Medical Center Rotterdam, Rotterdam, the Netherlands

${ }^{137}$ icoMetrix NV, Leuven, Belgium

${ }^{138}$ Movement Science Group, Faculty of Health and Life Sciences, Oxford Brookes University, Oxford, UK

${ }^{139}$ Psychology Department, Antwerp University Hospital, Edegem, Belgium

${ }^{140}$ Director of Neurocritical Care, University of California, Los Angeles, USA

${ }^{141}$ Department of Neurosurgery, St.Olavs Hospital, Trondheim University Hospital, Trondheim, Norway

${ }^{142}$ Department of Emergency Medicine, University of Florida, Gainesville, Florida, USA

${ }^{143}$ Department of Neurosurgery, Charité - Universitätsmedizin Berlin, corporate member of Freie Universität Berlin, Humboldt-Universität zu Berlin, and Berlin Institute of Health, Berlin, Germany

${ }^{144}$ VTT Technical Research Centre, Tampere, Finland

${ }^{145}$ Section of Neurosurgery, Department of Surgery, Rady Faculty of Health Sciences, University of Manitoba, Winnipeg, MB, Canada

\section{Author contributions}

GC conceived and supervised the project, participated in the data analysis, revised the first version of the manuscript the manuscript, and the supplementary tables. CR participated in the data analysis, drafted the manuscript, the supplementary tables and collected the COls. SG, MP, and PR analysed the data, drafted the manuscript, and the supplementary material. LM, ER, DKM, and NS were an active part of the manuscript drafting and revision. GC, CR, SG, MP, PR have verified the underlying data. DKM was one of the two coordinators of the CENTER-TBI study, and GC and NS were Work Package leaders. GC, $\mathrm{CR}, \mathrm{SG}$ and DKM discussed the findings with all the authors. All co-authors gave substantial feedback on the manuscript and approved the final version of it.

\section{Funding}

Open access funding provided by Università degli Studi di Milano - Bicocca within the CRUI-CARE Agreement. The Collaborative European NeuroTrauma Effectiveness Research in Traumatic Brain Injury (CENTER-TBI study, registered at clinicaltrials.gov NCT02210221) was funded by the FW7 program of the European Union (602150). Additional funding was obtained from the Hannelore Kohl Stiftung (Germany), from OneMind (USA) and Integra LifeSciences Corporation (USA). The funder had no role in the design of the study, the collection, analysis, and interpretation of data, or in writing the manuscript.

\section{Declarations}

\section{Conflict of interest}

GC reports grants, personal fees as Speakers' Bureau Member and Advisory Board Member from Integra and Neuroptics. DKM reports grants from the European Union and UK National Institute for Health Research, during the conduct of the study; grants, personal fees, and non-financial support from GlaxoSmithKline; personal fees from Neurotrauma Sciences, Lantmaanen AB, Pressura, and Pfizer, outside of the submitted work. The other authors declare that they have no competing interests.

\section{Ethics approval and consent to participate}

The Medical Ethics Committees of all participating centers approved the CENTER-TBI study, and informed consent was obtained according to local regulations. (https://www.center-tbi.eu/project/ethical-approval).

\section{Open Access}

This article is licensed under a Creative Commons Attribution-NonCommercial 4.0 International License, which permits any non-commercial use, sharing, adaptation, distribution and reproduction in any medium or format, as long as you give appropriate credit to the original author(s) and the source, provide a link to the Creative Commons licence, and indicate if changes were made. The images or other third party material in this article are included in the article's Creative Commons licence, unless indicated otherwise in a credit line to the material. If material is not included in the article's Creative Commons licence and your intended use is not permitted by statutory regulation or exceeds the permitted use, you will need to obtain permission directly from the copyright holder. To view a copy of this licence, visit http://creativecommons.org/licen ses/by-nc/4.0/.

\section{Publisher's Note}

Springer Nature remains neutral with regard to jurisdictional claims in published maps and institutional affiliations.

\section{Received: 28 May 2021 Accepted: 26 June 2021}

Published online: 24 July 2021

\section{References}

1. Hoiland RL, Fisher JA, Ainslie PN (2019) Regulation of the Cerebral Circulation by Arterial Carbon Dioxide. In: Compr. Physiol. Wiley. https://doi.org/ 10.1002/cphy.c180021

2. Gouvea Bogossian E, Peluso L, Creteur J, Taccone FS (2021) Hyperventilation in Adult TBI Patients: How to Approach It? Neurol Front. https://doi. org/10.3389/fneur.2020.580859

3. Lundberg N, Kjallquist A, Bien C (1949) Reduction of increased intracranial pressure by hyperventilation. A therapeutic aid in neurological surgery, Acta Psychiatr. Scand. Suppl. 34:1-64. http://www.ncbi.nlm.nih.gov/ pubmed/14418913.

4. Godoy DA, Seifi A, Garza D, Lubillo-Montenegro S, Murillo-Cabezas F (2017) Hyperventilation Therapy for Control of Posttraumatic Intracranial Hypertension. Front Neurol. https://doi.org/10.3389/fneur.2017.00250

5. Stocchetti N, Maas AIR, Chieregato A, van der Plas AA (2005) Hyperventilation in Head Injury. Chest 127:1812-1827. https://doi.org/10.1378/ chest.127.5.1812 
6. Stocchetti N, Carbonara M, Citerio G, Ercole A, Skrifvars MB, Smielewski P, Zoerle T, Menon DK (2017) Severe traumatic brain injury: targeted management in the intensive care unit. Lancet Neurol 16:452-464. https:// doi.org/10.1016/S1474-4422(17)30118-7

7. Coles JP, Minhas PS, Fryer TD, Smielewski P, Aigbirihio F, Donovan T, Downey SPMJ, Williams G, Chatfield D, Matthews JC, Gupta AK, Carpenter TA, Clark JC, Pickard JD, Menon DK (2002) Effect of hyperventilation on cerebral blood flow in traumatic head injury: clinical relevance and monitoring correlates*. Crit Care Med 30:1950-1959. https://doi.org/10.1097/ 00003246-200209000-00002

8. Curley G, Kavanagh BP, Laffey JG (2010) Hypocapnia and the injured brain: More harm than benefit. Crit Care Med 38:1348-1359. https://doi. org/10.1097/CCM.0b013e3181d8cf2b

9. Cnossen MC, Huijben JA, van der Jagt M, Volovici V, van Essen T, Polinder S, Nelson D, Ercole A, Stocchetti N, Citerio G, Peul WC, Maas AIR, Menon D, Steyerberg EW, Lingsma HF (2017) Variation in monitoring and treatment policies for intracranial hypertension in traumatic brain injury: a survey in 66 neurotrauma centers participating in the CENTER-TBI study. Crit Care 21:233. https://doi.org/10.1186/s13054-017-1816-9

10. N Carney, AM Totten, C OReilly, JS Ullman, GWJ Hawryluk, MJ Bell, SL Bratton, R Chesnut, OA Harris, N Kissoon, AM Rubiano, L Shutter, RC Tasker, MS Vavilala, J Wilberger, DW Wright, J Ghajar (2017) Guidelines for the Management of Severe Traumatic Brain Injury, Fourth Edition. Neurosurgery. https://doi.org/10.1227/NEU.0000000000001432.

11. Roberts I, Schierhout G (1997) Hyperventilation therapy for acute traumatic brain injury. Cochrane Database Syst Rev. https://doi.org/10.1002/ 14651858.CD000566

12. Robba C, Poole D, McNett M, Asehnoune K, Bösel J, Bruder N, Chieregato A, Cinotti R, Duranteau J, Einav S, Ercole A, Ferguson N, Guerin C, Siempos II, Kurtz P, Juffermans NP, Mancebo J, Mascia L, McCredie V, Nin N, Oddo M, Pelosi P, Rabinstein AA, Neto AS, Seder DB, Skrifvars MB, Suarez Jl, Taccone FS, van der Jagt M, Citerio G, Stevens RD (2020) Mechanical ventilation in patients with acute brain injury: recommendations of the European Society of Intensive Care Medicine consensus. Intensive Care Med. https://doi.org/10.1007/s00134-020-06283-0

13. Hawryluk GWJ, Aguilera S, Buki A, Bulger E, Citerio G, Cooper DJ, Arrastia RD, Diringer M, Figaji A, Gao G, Geocadin R, Ghajar J, Harris O, Hoffer A, Hutchinson P, Joseph M, Kitagawa R, Manley G, Mayer S, Menon DK, Meyfroidt G, Michael DB, Oddo M, Okonkwo D, Patel M, Robertson C, Rosenfeld JV, Rubiano AM, Sahuquillo J, Servadei F, Shutter L, Stein D, Stocchetti N, Taccone FS, Timmons S, Tsai E, Ullman JS, Vespa P, Videtta W, Wright DW, Zammit C, Chesnut RM (2019) A management algorithm for patients with intracranial pressure monitoring: the Seattle International Severe Traumatic Brain Injury Consensus Conference (SIBICC). Intensive Care Med. https://doi.org/10.1007/s00134-019-05805-9

14. Maas AIR, Menon DK, Steyerberg EW, Citerio G, Lecky F, Manley GT, Hill S, Legrand V, Sorgner A (2015) Collaborative European NeuroTrauma Effectiveness Research in Traumatic Brain Injury (CENTER-TBI). Neurosurgery. https://doi.org/10.1227/NEU.0000000000000575

15. Steyerberg EW, Wiegers E, Sewalt C, et al (2019) Case-mix, care pathways, and outcomes in patients with traumatic brain injury in CENTER-TBI: a European prospective, multicentre, longitudinal, cohort study. Lancet Neurol. https://doi.org/10.1016/S1474-4422(19)30232-7

16. Huijben JA, Wiegers EJA, Lingsma HF, Citerio G, Maas AIR, Menon DK, Ercole A, Nelson D, van der Jagt M, Steyerberg EW, Helbok R, Lecky F,
Peul W, Birg T, Zoerle T, Carbonara M, Stocchetti N (2020) Changing care pathways and between-center practice variations in intensive care for traumatic brain injury across Europe: a CENTER-TBI analysis. Intensive Care Med 46:995-1004. https://doi.org/10.1007/s00134-020-05965-z

17. Huijben JA, Dixit A, Stocchetti N, Maas AIR, Lingsma HF, van der Jagt $M$, Nelson D, Citerio G, Wilson L, Menon DK, Ercole A (2021) Use and impact of high intensity treatments in patients with traumatic brain injury across Europe: a CENTER-TBI analysis. Crit Care 25:78. https://doi.org/10.1186/ s13054-020-03370-y

18. Wilson JTL, Pettigrew LEL, Teasdale GM (1998) Structured Interviews for the Glasgow Outcome Scale and the Extended Glasgow Outcome Scale: Guidelines for Their Use. J Neurotrauma. https://doi.org/10.1089/neu. 1998.15 .573

19. Maas AIR, Marmarou A, Murray GD, Teasdale SGM, Steyerberg EW (2007) Prognosis and Clinical Trial Design in Traumatic Brain Injury: The IMPACT Study. J Neurotrauma 24:232-238. https://doi.org/10.1089/neu.2006.0024

20. Cnossen M, van Essen TA, Ceyisakar IE, Polinder S, Andriessen T, van der Naalt J, Haitsma I, Horn J, Franschman G, Vos P, Peul W, Menon DK, Maas A, Steyerberg E, Lingsma H (2018) Adjusting for confounding by indication in observational studies: a case study in traumatic brain injury. Clin Epidemiol 10:841-852. https://doi.org/10.2147/CLEP.S154500

21. Vik A, Nag T, Fredriksli OA, Skandsen T, Moen KG, Schirmer-Mikalsen K, Manley GT (2008) Relationship of "dose" of intracranial hypertension to outcome in severe traumatic brain injury. J Neurosurg 109:678-684. https://doi.org/10.3171/JNS/2008/109/10/0678

22. Muizelaar JP, Marmarou A, Ward JD, Kontos HA, Choi SC, Becker DP, Gruemer H, Young HF (1991) Adverse effects of prolonged hyperventilation in patients with severe head injury: a randomized clinical trial. J Neurosurg. https://doi.org/10.3171/jns.1991.75.5.0731

23. Coles JP, Fryer TD, Coleman MR, Smielewski P, Gupta AK, Minhas PS, Aigbirhio F, Chatfield DA, Williams GB, Boniface S, Carpenter TA, Clark JC, Pickard JD, Menon DK (2007) Hyperventilation following head injury: Effect on ischemic burden and cerebral oxidative metabolism*. Crit Care Med. https://doi.org/10.1097/01.CCM.0000254066.37187.88

24. Brandi G, Stocchetti N, Pagnamenta A, Stretti F, Steiger P, Klinzing S (2019) Cerebral metabolism is not affected by moderate hyperventilation in patients with traumatic brain injury. Crit Care. https://doi.org/10.1186/ s13054-018-2304-6

25. Diringer MN, Videen TO, Yundt K, Zazulia AR, Aiyagari V, Dacey RG, Grubb RL, Powers WJ (2002) Regional cerebrovascular and metabolic effects of hyperventilation after severe traumatic brain injury. J Neurosurg 96:103-108. https://doi.org/10.3171/jns.2002.96.1.0103

26. Diringer MN, Yundt K, Videen TO, Adams RE, Zazulia AR, Deibert E, Aiyagari V, Dacey RG, Grubb RL, Powers WJ (2000) No reduction in cerebral metabolism as a result of early moderate hyperventilation following severe traumatic brain injury. J Neurosurg 92:7-13. https://doi.org/10. 3171/jns.2000.92.1.0007

27. Neumann J-O, Chambers IR, Citerio G, Enblad P, Gregson BA, Howells T, Mattern J, Nilsson P, Piper I, Ragauskas A, Sahuquillo J, Yau YH, Kiening K (2008) The use of hyperventilation therapy after traumatic brain injury in Europe: an analysis of the brain database. Intensive Care Med 34:1676. https://doi.org/10.1007/s00134-008-1123-7

28. Gordon E (1971) Controlled respiration in the management of patients with traumatic brain injuries. Acta Anaesthesiol Scand. https://doi.org/10. 1111/j.1399-6576.1971.tb05461.x 